NBER WORKING PAPER SERIES

DIVERGING TRENDS IN MACRO AND MICRO VOLATILITY: FACTS

Diego Comin

Sunil Mulani

Working Paper 10922

http://www.nber.org/papers/w10922

NATIONAL BUREAU OF ECONOMIC RESEARCH

1050 Massachusetts Avenue

Cambridge, MA 02138

November 2004

The views expressed herein are those of the author(s) and do not necessarily reflect the views of the National Bureau of Economic Research.

(C) 2004 by Diego Comin and Sunil Mulani. All rights reserved. Short sections of text, not to exceed two paragraphs, may be quoted without explicit permission provided that full credit, including $\odot$ notice, is given to the source. 
Diverging Trends in Macro and Micro Volatility: Facts

Diego Comin and Sunil Mulani

NBER Working Paper No. 10922

November 2004

JEL No. E3, F1, D2

\begin{abstract}
$\underline{\text { ABSTRACT }}$
This paper documents the diverging trends in volatility of the growth rate of sales at the aggregate and firm level. We establish that the upward trend in micro volatility is not simply driven by a compositional bias in the sample studied. We argue that this new fact sheds some shadows on the proposed explanations for the decline in aggregate volatility and that, given the symmetry of the diverging trends at the micro and macro level, a common explanation is likely. We conclude by describing one such theory.

Diego Comin

Department of Economics

New York University

269 Mercer Street, 725

New York, NY 10003

and NBER

diego.comin@nyu.edu

Sunil Mulani

Analysis Group

sunil@mulani.net
\end{abstract}




\title{
Diverging Trends in Macro and Micro Volatility: Facts*
}

\author{
Diego Comin ${ }^{\dagger}$ and Sunil Mulani ${ }^{\ddagger}$
}

December 3, 2004

\begin{abstract}
This paper documents the diverging trends in volatility of the growth rate of sales at the aggregate and firm level. We establish that the upward trend in micro volatility is not simply driven by a compositional bias in the sample studied. We argue that this new fact sheds some shadows on the proposed explanations for the decline in aggregate volatility and that, given the symmetry of the diverging trends at the micro and macro level, a common explanation is likely. We conclude by describing one such theory.
\end{abstract}

Keywords: Firm-Level Volatility, Aggregate Volatility, COMPUSTAT.

JEL Classification: E3, F1, D2.

\section{Introduction}

The volatility of macroeconomic variables has received increasing interest in recent years. McConnell and Perez-Quiros [2000] showed that the volatility of GDP has declined significantly since the mid 1980's. Blanchard and Simon [2002] established the presence of a downward trend in the volatility of GDP beginning in the 50's with an interruption in the 70's. In addition, Stock and Watson [2002]

${ }^{*}$ We thank the excellent research assistance provided by Ted Rosenbaum. We also appreciate the helpful comments of three anonymous referees and Daron Acemoglu (the Editor). We have benefited from discussions with Olivier Blanchard, Bob Hall, Hyunbae Chun, Xavier Gabaix, Boyan Jovanovic, John Leahy, Meg McConnell and Thomas Philippon and from the suggestions of seminar participants at Stern, the New York Fed and the NBER Summer Institute. Comin thanks the hospitality of the New York Federal Reserve Bank and the support of the C.V. Starr Center. The view presented in these paper are not necessarily those of the Federal Reserve.

${ }^{\dagger}$ New York University, NBER and New York Federal Reserve Bank.

$\ddagger$ Analysis Group 
analyzed the time series of 124 macro variables since 1960 and found that the decline in aggregate volatility, beginning in 1984, is pervasive.

In an attempt to increase our understanding of volatility, this paper examines its evolution at the micro level. Specifically, the volatility of growth rate of sales at the firm level is examined using the COMPUSTAT data base, and compared to the aforementioned evolution of volatility at the aggregate level. The main finding is that while the growth rate of aggregate sales has become more stable, the growth rate of sales at the firm level has become more volatile. Put differently, volatility at the aggregate and firm level have followed diverging trends. ${ }^{1}$

Several exercises are undertaken to verify the robustness of the upward trend in firm-level volatility. An important concern when using a sample of firms gathered from COMPUSTAT database to establish firm-level facts is whether it is representative of firms in the US economy. In section 2.2, we argue that the upward trend in volatility is not simply the result of changes in the composition of the sample that are not reflected in the economy. This is done by showing that the upward trend persists after removing the predictable effect of age and size on the firm-level volatility and after including firm-level fixed effects. Section 2.3 addresses the evolution of firm-level volatility across different sectors and finds that most sectors exhibit the upward trend.

Having verified the robustness of the upward trend in firm-level volatility, focus is shifted to the volatility at the aggregate level. We examine the volatility of aggregate sales in the COMPUSTAT sample (our sample). The aggregate volatility of our sample exhibits a mild decline in comparison to volatility of aggregate final sales. ${ }^{2}$ To gain further insight into the "mechanical" determinants of this pattern, a variance decomposition is undertaken. In addition, evolution of volatility for other sub-samples of GDP, such as the sales at the sector level, is examined.

Section 4 briefly addresses the cyclical patterns of volatility observing that both the aggregate and firm-level volatility of sales (and sales per worker) are pro-cyclical, albeit the maximum cross

\footnotetext{
${ }^{1}$ There exists some prior evidence of increasing uncertainty in the firm's economic environment. Comin [2000] finds that the volatility of individual stock returns has increased (almost) monotonically since the 1950's. Campbell et al. [2001] find the same upward trend in firm specific risk i.e. the cross-sectional dispersion of the the component of returns that is orthogonal to the average return in the 4-digit sector. However, aggregate stock returns have also become more volatile. The volatility of monthly aggregate stock returns in the US markets (measured by the standard deviation of a ten year rolling window of returns) remained low between the end of WWII and 1968. It then increased, reaching a high plateau, between 1968 and 1983. It declined over the next decade until 1993, after which it restarted its increase reaching the high volatility levels of the 70's.

${ }^{2}$ Aggregate Final Sales refers to Final Sales of Domestic Product, gathered from the Bureau of Economic Analysis (BEA).
} 
correlation between aggregate volatility and output seems to take place with a longer lag than for firm-level volatility.

We conclude the paper by using our empirical findings to evaluate the explanations proposed to understand the decline in aggregate volatility. These explanations can be divided in two groups. The first group attempts to explain the decline in macro volatility through mechanisms that lead to a decline in volatility at the firm level and then, trivially, aggregate up the micro trends. The second group of explanations attempts to directly explain the decline in macro volatility. Both of these approaches are unsatisfactory in the light of the facts presented in this paper. The first is at odds with the increase in micro volatility. The second, though not inconsistent, is insufficient to account per se for the upward trend in firm-specific uncertainty. To fill this gap, we propose a new explanation that simultaneously accounts for the opposite trends observed in micro and macro volatility.

\section{Firm-Level Volatility}

Consider the time series for a random variable $X_{t}$. The volatility of $X_{t}$ is defined as the time-series of standard deviations of ten-year rolling windows of $X_{t}$. Formally, we compute the time series for the volatility of $X_{t}$ as:

$$
\sigma\left(X_{t}\right)=\sqrt{\frac{\sum_{\tau=t-4}^{t+5}\left(X_{\tau}-\bar{X}_{t}\right)^{2}}{10}},
$$

where $\bar{X}_{t}$ is the average of $X_{t}$ between $t-4$ and $t+5$.

In order to examine volatility at the firm level, annual data on Net Sales is gathered for a sample of firms extracted from COMPUSTAT, comprising of publicly traded companies between 1950 and 2002. ${ }^{3}$ The sample is restricted to companies that have non-zero values of Net Sales for any of the years in the sample period. Both currently active as well as inactive companies are included in the sample whereas international firms are eliminated. ${ }^{4}$ Also eliminated are companies that exhibit

\footnotetext{
${ }^{3}$ Standard \& Poor's COMPUSTAT North America is a database of financial, statistical and market information covering publicly traded companies in the U.S. and Canada. Net Sales is defined as gross sales (the amount of actual billings to customers for regular sales completed during the year) reduced by cash discounts, trade discounts, and returned sales and allowances for which credit is given to customers.

${ }^{4}$ Sensitivity tests were performed by varying the characteristics of the firms included in the sample along the following lines (i) companies with non-zero Net Sales vs. Net Sales greater than 1 Million, (ii) only active companies
} 


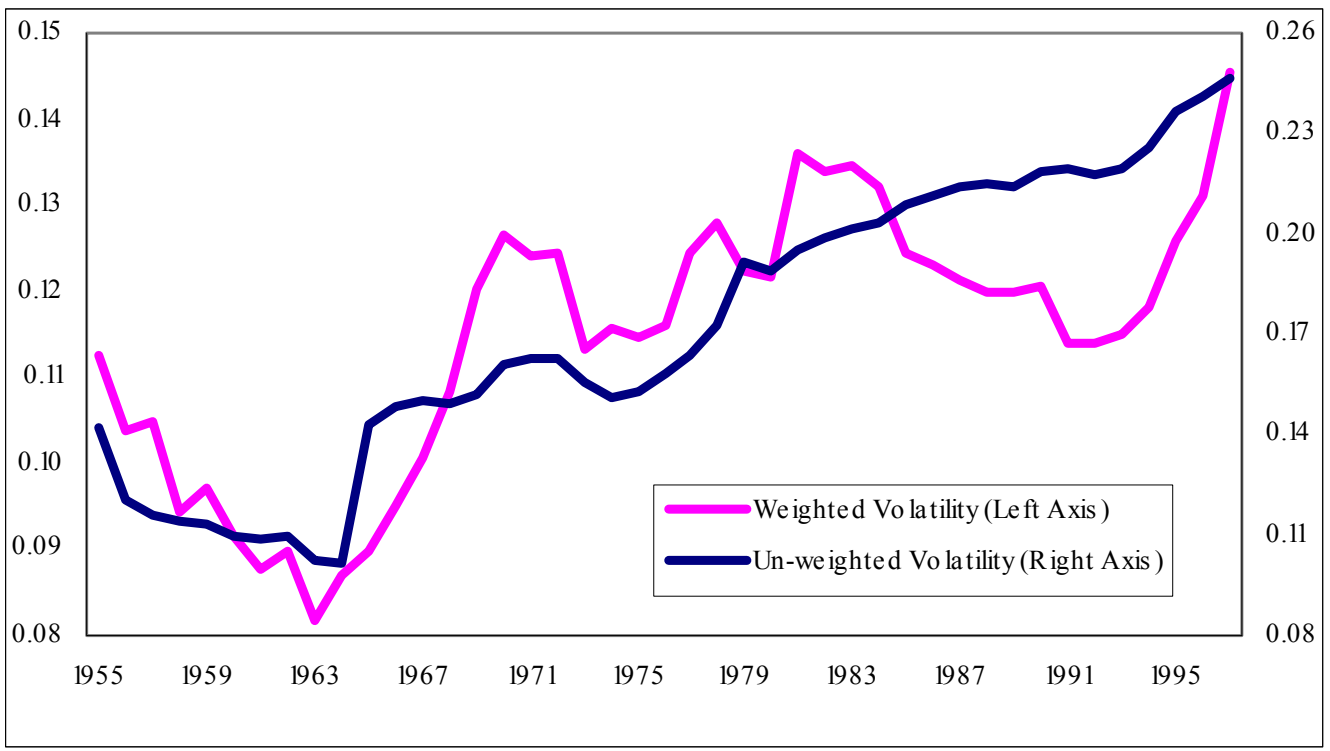

Figure 1: Volatility of the Growth Rate of Real Firm-Level Sales

gaps in annual data on Net Sales or that do not have eleven years of sales in sample. Total sales by year for the remaining firms constitute, on average, $78 \%$ of GDP.

For every firm, the series $\sigma\left(\gamma_{\text {sales }_{i t}}\right)$ is computed, where $\gamma_{\text {sales }_{i t}}$ represents the growth rate of real sales for the company, the deflator being the aggregate producer price index (PPI). These standard deviations are then averaged across all the firms in a year to arrive at the average volatility for every year. ${ }^{5}$ As illustrated in Figure 1, volatility at the firm level exhibits a significant upward trend. In order to build a more representative measure of volatility, they are weighed using the firm's share of sales in total sales in a given year. Figure 1 also shows the persistent upward trend after the use of these weights.

The source of this increase in volatility, however, may be subject to question. While the upward vs. both active and inactive companies and (iii) including or excluding foreign companies. The results are consistent across the combinations of sample characteristics.

${ }^{5}$ Another way of measuring the volatility inherent in the firm's environment is by focusing on the cross-section as Campbell et al. [2001]. Specifically, we could compute standard deviations of growth rates across all the firms in a given year. We believe that the time series measure of volatility used in this paper is more appealing since it is less likely to be affected by compositional biases. When computing the standard deviation of the window in the time series, we remove the average growth rate for the firm in the window, and in effect control for firm specific aspects that affect the growth rate of sales. These aspects, however, potentially show up in the cross sectional measure and may be the medium through which a compositional bias operates. 


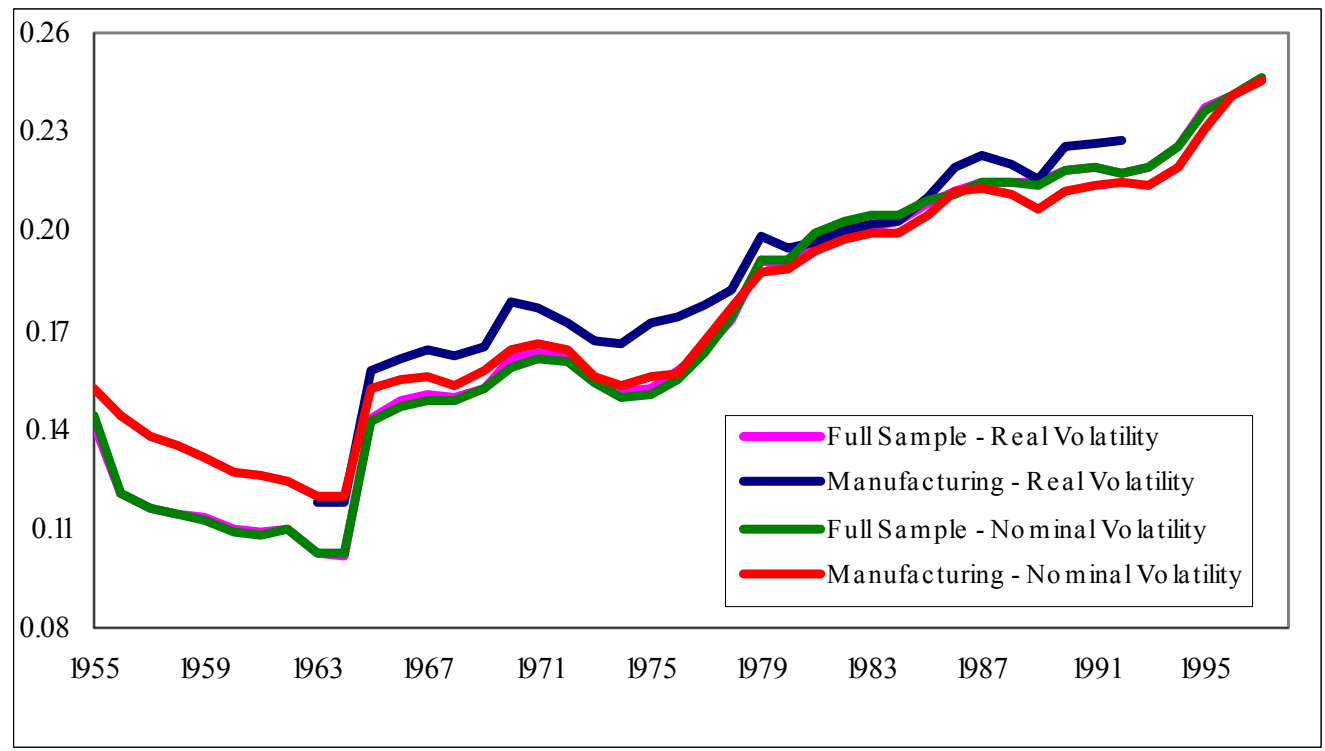

Figure 2: Comparison of Un-weighted Volatility in Full Sample and Manufacturing Sub-Sample.

trend may, as we claim, accurately reflect changes in the economy, the increase in volatility may be a feature specific only to the sample or the variable in use. Our claims necessitate discrediting these possibilities.

\subsection{Bias Due to Price Divergence}

The lack of price deflators at the firm level has, thus far, made impossible an analysis of the growth rate of nominal sales in real terms. There exists then the possibility that the increase in volatility may be driven by a divergence in the prices at the firm level. ${ }^{6}$ To address this issue, two exercises are undertaken. First, a subset of our sample is created, comprising of all firms in the manufacturing sector (sub-sample). For this sub-sample of firms, Net Sales are adjusted using deflators at the 4digit level. ${ }^{7}$ Figure 2 presents the average volatility of the growth rate of nominal and real firm-level sales for both the full and the manufacturing sub-sample. Figure 3 reflects weighted measures for the same variable.

Two conclusions are drawn from these figures. First, the evolution of the average volatility for the growth rate of nominal sales for firms in the full sample and firms in the manufacturing sub-

\footnotetext{
${ }^{6}$ As will be evident in figure 2, CPI inflation plays no role in the volatility of the growth rate of nominal sales at the firm level.

${ }^{7}$ Deflators for sales at the 4-digit level are acquired from the NBER manufacturing dataset.
} 


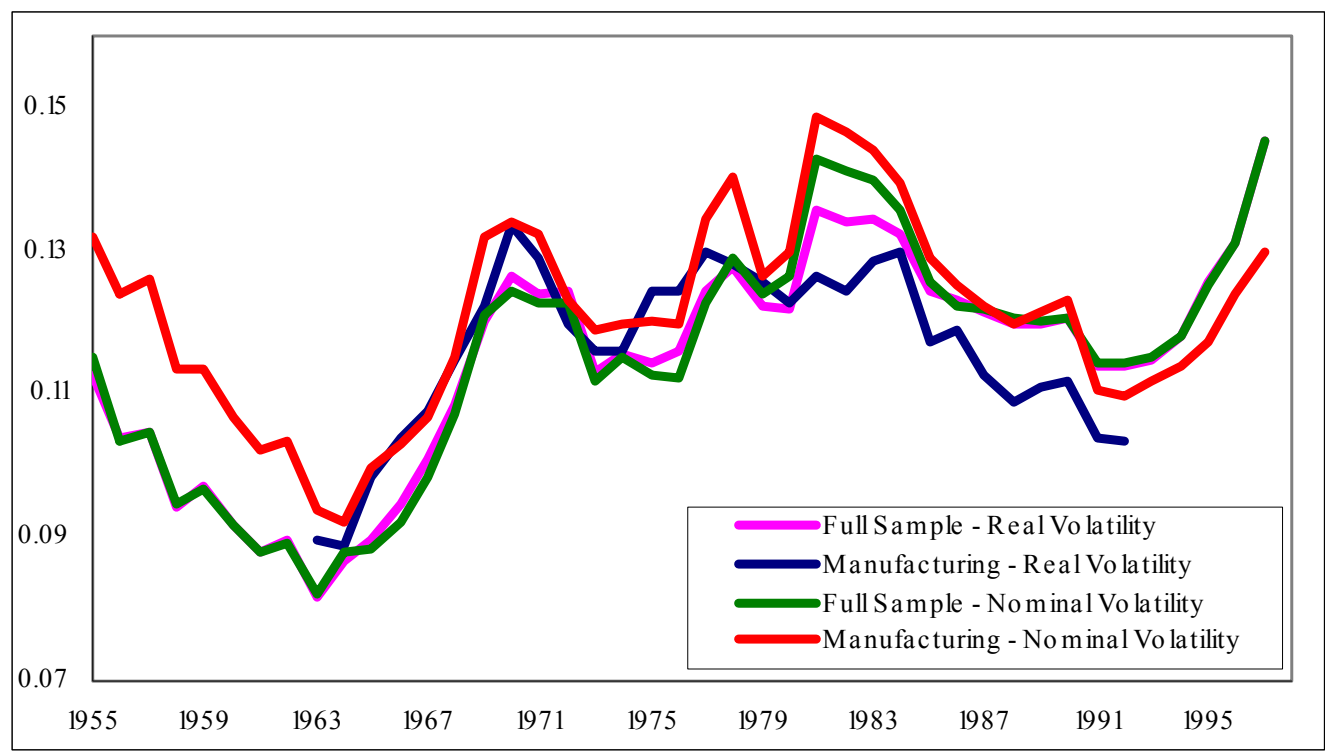

Figure 3: Comparison of Weighted Volatility in Full Sample and in Manufacturing Sub-Sample.

sample, is similar. Second, in the manufacturing sector, the evolution of volatility for the growth rate of nominal and real sales is the same.

While this result does not eliminate the possibility that the upward trend in volatility is driven by firm-level price divergence, it suggests that the divergence operates, if at all, within 4-digit sectors, a scenario we consider unlikely. However, to rule out this possibility, a more "real" measure of input for the firm is examined in the form of employment. ${ }^{8}$ Figure 4 plots the evolution of the weighted and un-weighted measures of volatility for the growth rate of employment at the firm-level. The upward trends are evident.

\subsection{Controlling for Changes in the Sample Composition}

The sample used ranges from 1950 through 2002 and is extracted from the COMPUSTAT database. The size of the sample increases drastically in the 1970's raising the possibility that the upward trend in the firm-level volatility is the result of a compositional bias. Firms that are incorporated in the data set in the post-1970's period are potentially more volatile than the firms in the pre70's period either because the sector in which they operate is more volatile, or on account of firm specific attributes such as being younger or smaller. In order to show that the upward trend in micro

\footnotetext{
${ }^{8}$ Data on number of employees is also gathered from COMPUSTAT using the same criteria.
} 


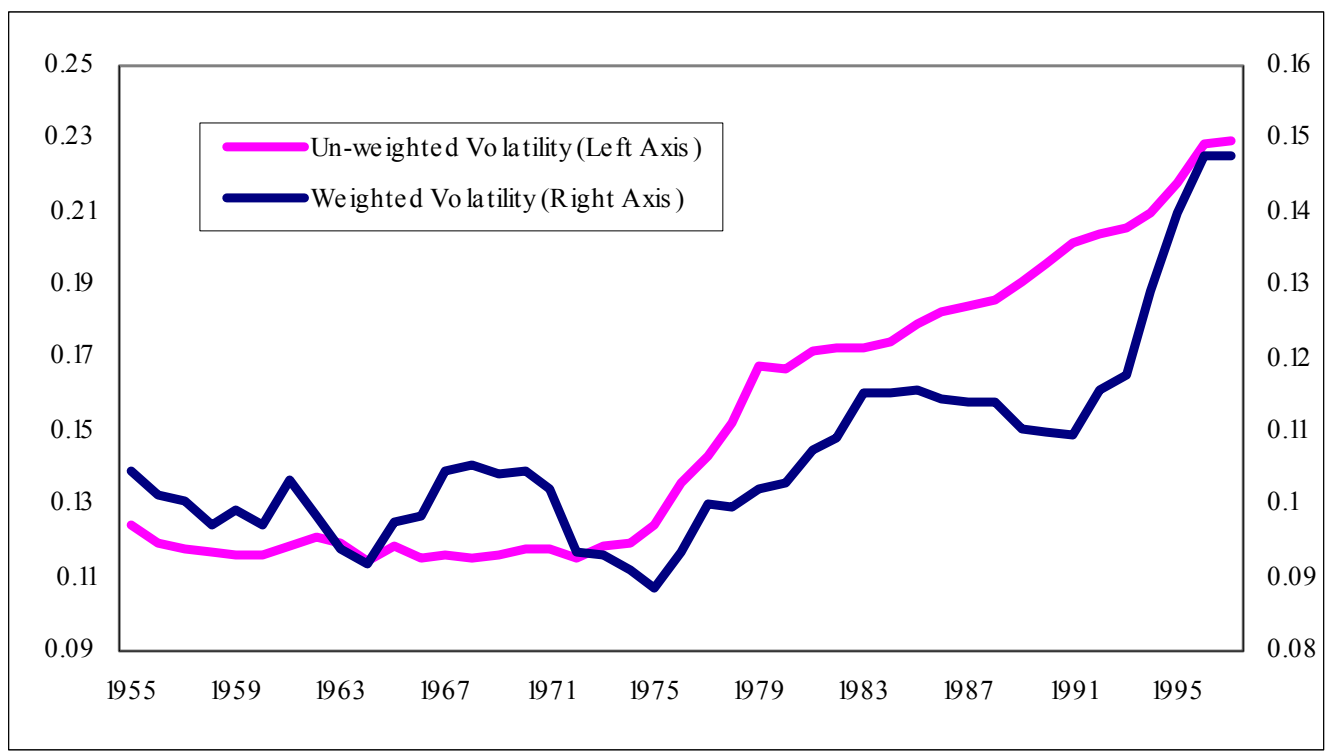

Figure 4: Volatility of Growth Rate of Number of Employees

volatility is not due to a compositional bias in the sample studied, three exercises are undertaken. ${ }^{9}$

First, the sample of firms is divided up at any point in time in to five quintiles according to the level of sales to examine whether the increase in volatility is driven by any specific quintile or whether it holds across the distribution. Comin and Mulani [2003] shows that the increase in firmlevel volatility is not confined to any one section of the distribution but is rather pervasive across the sample. This finding, though, does not necessarily negate the compositional bias argument. In theory, given the higher probability of sampling smaller (and/or younger) firms in the post-1970 period, all the quintiles may be composed to a larger extent of smaller, more volatile firms.

Hence, as a second exercise, we focus our analysis on the component of volatility that is not explained by firm-level characteristics that are changing in the sample. Specifically, we run a pooled regression of the firm-level standard deviations $\left(\sigma_{i t}\right)$ on a vector of the firms characteristics $\left(X_{i t}\right)$ that contains the log of the share of firm sales in GDP and the log of the firm's age.

$$
\sigma_{i t}=\alpha_{0}+\alpha_{1} X_{i t}+\epsilon_{i t}^{\sigma}
$$

The unpredictable component of volatility $\left(\epsilon_{i t}^{\sigma}\right)$ is then aggregated, resulting in a time series for firm-level volatility. As in the previous section, both weighted and un-weighted measures of residual

\footnotetext{
${ }^{9}$ An alternative approach is to track down the evolution of the volatility of the firms initially in sample but this would generate survivorship bias.
} 


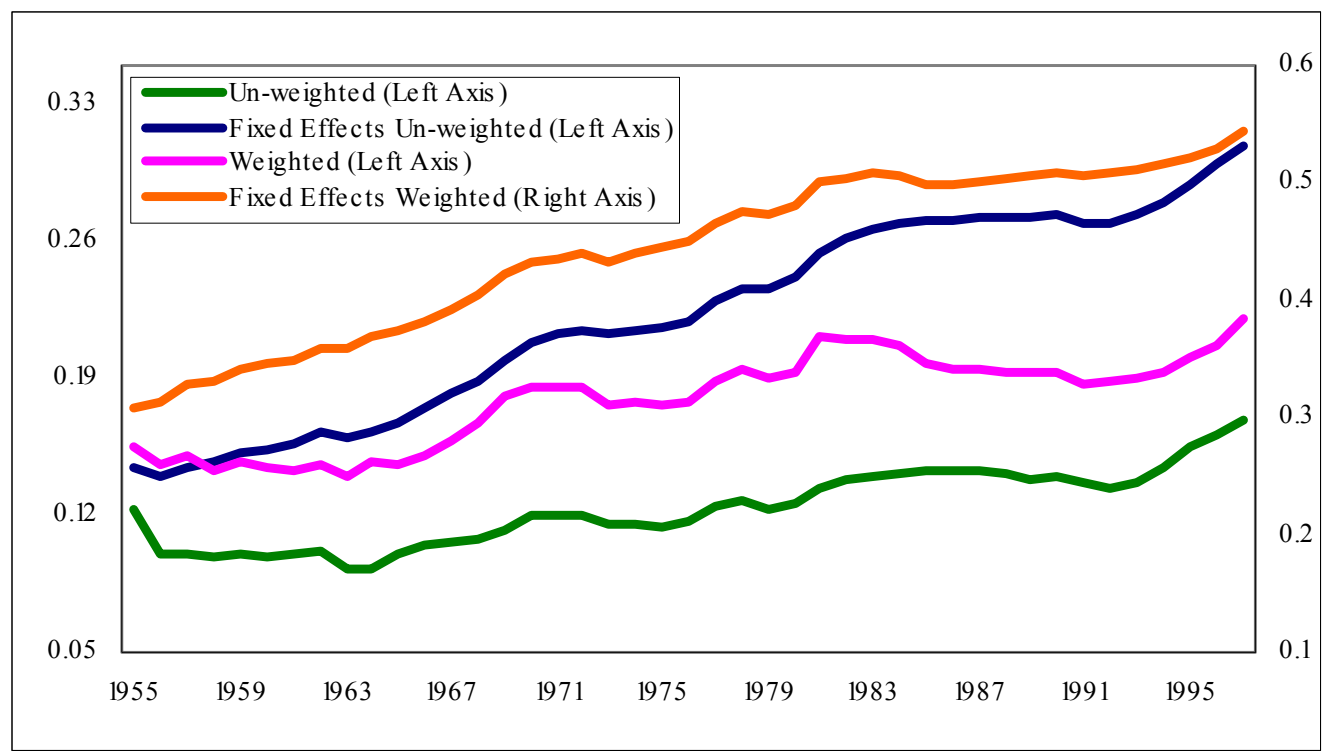

Figure 5: Residual Volatility after Controlling for $\log ($ age) and $\log ($ size).

volatility are considered, where the weights are given by the firm's share in total sales in the year. Figure 5 plots the prominent upward trend in residual volatility, though there is a flattening of the trend during the 80's and 90's in the weighted measures.

The evidence presented thus far refutes the hypothesis that the observed upward trend in firmspecific uncertainty is simply the result of the inclusion of a larger share of smaller or younger (more volatile) firms in the sample since 1970. However, it may still be argued that factors other than size or age induce higher volatility in the new population of firms sampled leading to a compositional bias. To rule out this possibility, as a third exercise, firm dummies are used to eliminate the effect of firm specific variables (both observable and unobservable) on volatility. Removing this firm specific component of volatility leaves only the component that is orthogonal to fixed firm characteristics and therefore immune to any compositional bias in the sample. ${ }^{10}$

Note that this exercise constitutes a stringent test of the upward trend in micro volatility hypothesis. To illustrate this point, suppose that our hypothesis is true and the upward trend is due to the fact that new firms in the economy are just more volatile. Removing the firm-specific component of all the firms in sample eliminates the component that is more volatile for new firms - the precise component we are looking to examine. Nevertheless, using a firm fixed effect in the regression is an informative exercise because if the upward trend still holds, a compositional bias

\footnotetext{
${ }^{10}$ One such bias is the associated with the change in the industry composition of the sample.
} 
can be ruled out as a driver of the upward trend.

Formally, we run the following regression where $\alpha_{i}$ is a set of firm specific dummies and the set of controls included in $X_{i t}$ contains the log of age and the log of the share of sales in GDP.

$$
\sigma_{i t}=\alpha_{i}+\beta X_{i t}+\epsilon_{i t}^{\sigma}
$$

Figure 5 also plots the average residual volatility series $\left(\epsilon_{t}^{\sigma}\right)$. Even after removing the firm specific component in volatility, the upward trend persists.

\subsection{Firm-level Volatility by Sectors}

Having verified the robustness of the upward trend in volatility, we investigate whether the increase in volatility is pervasive or whether instead it is limited to a few sectors. To address this question, the following regressions are run for each two-digit sector:

$$
\begin{aligned}
\sigma_{i t} & =\alpha+\beta X_{i t}+\delta D_{s t}+\epsilon_{i t}^{\sigma} \\
\sigma_{i t} & =\alpha_{i}+\beta X_{i t}+\delta D_{s t}+\epsilon_{i t}^{\sigma}
\end{aligned}
$$

where $D_{s t}$ is a set of sector specific time dummies. By running these regressions with and without firm weights, we can construct the time series for the weighted and non-weighted average firm-level volatility after controlling for the effect of age and size and (possibly) for a firm-specific intercept in volatility. For each two-digit sector Table 1 reports the average estimated coefficient on the year dummies for each decade from the regression with firm-level fixed effects. Table 1 shows that the upward trend in firm-level volatility is pervasive across sectors with the exception of construction. Results are very similar for the regressions without firm-specific intercepts.

\section{Aggregate Volatility}

The evolution of volatility at the aggregate level does not mirror the upward trend in firm-level volatility. Several authors have observed that a variety of macro variables have become more stable over the same time period. Figure 6 plots the time series of $\sigma($.$) for both the growth rate of nominal$ and real aggregate final sales from the BEA.

Several points are worth mentioning here. First, the growth rate of aggregate sales exhibits a significant decline in volatility beginning in the 1980's. Second, as emphasized by Blanchard and 


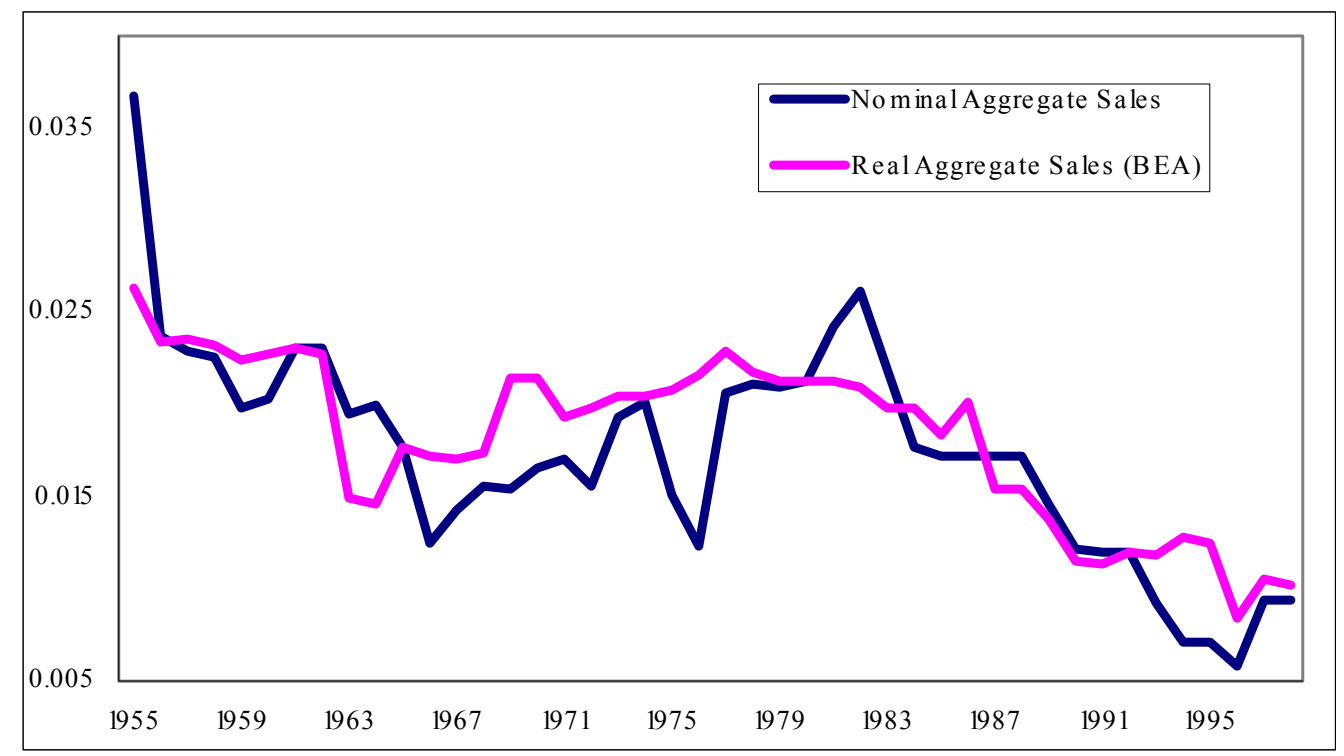

Figure 6: Volatility of Growth Rate of Aggregate Final Sales (BEA)

Simon [2002] for GDP, the time series volatility of aggregate sales is best characterized by a secular decline that started in the 1950's and was interrupted from the mid 60's through the 70's. Finally, given the similar downward trends in both nominal and real sales, inflation does not seem to be a significant issue.

When compared to volatility at the firm level (Figure 7), the secular diverging trends in the post-war period are evident. ${ }^{11}$

To understand the mechanics of the divergence in the evolution of volatility we decompose the variance of the aggregate growth rate of sales in the COMPUSTAT sample into a variance and a covariance component.

\subsection{Variance Decomposition}

Before undertaking the variance decomposition, we verify that our sample exhibits similar characteristics at the aggregate level as the aggregate final sales. Figure 8 plots the volatility of the growth rate of aggregate sales for the firms in the our sample. The downward trend in the volatility is not as prominent as for the volatility of GDP. There are two reasons for this. First, the growth rate

\footnotetext{
${ }^{11}$ The divergence persists at higher frequencies as well. The correlation between ten year rolling windows extracted from these two series is negative in more than two thirds of the windows.
} 


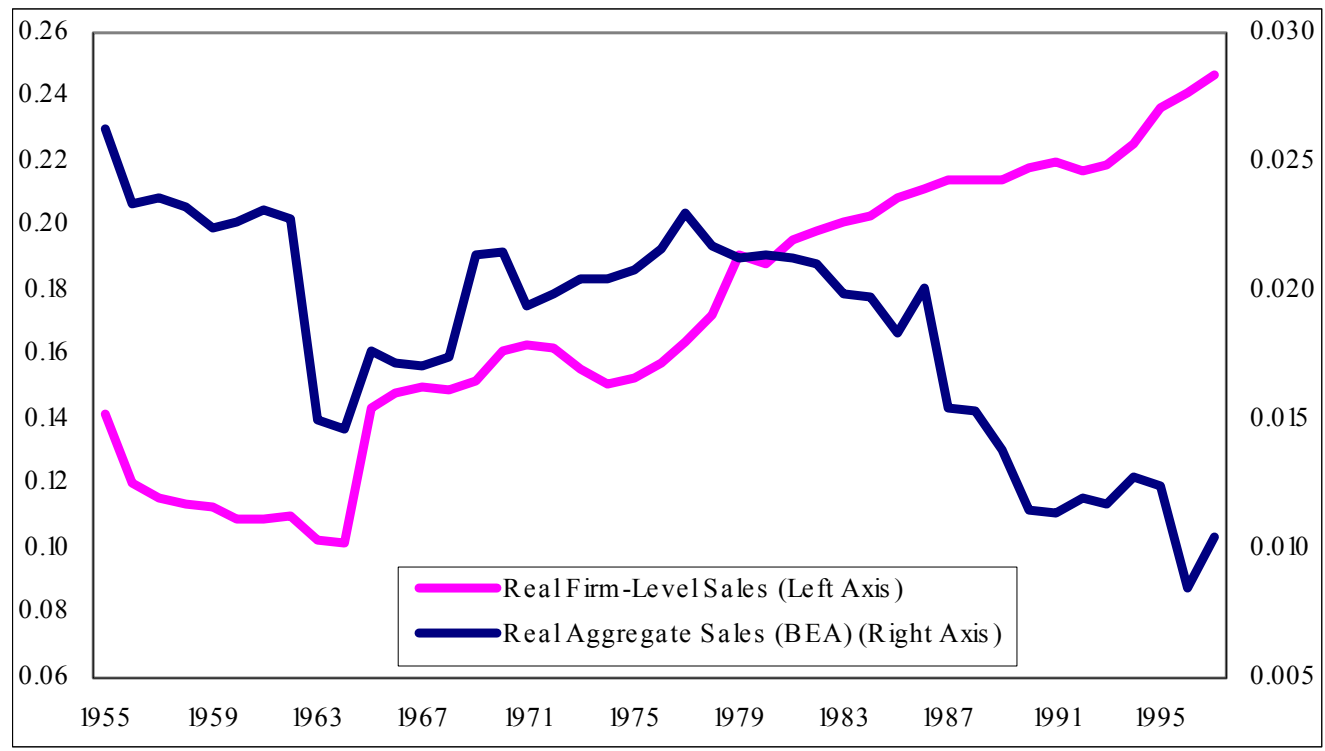

Figure 7: Volatility of Growth Rate of Aggregate Final Sales (BEA) and Firm-Level Sales

of total sales in the our sample varies as the comprehensiveness of the sample varies. Fluctuations in the comprehensiveness of the sample accentuated by the addition of firms incorporated in the NASDAQ will add noise to the growth rate of aggregate sales in the post 1970 period. This force may tend to induce an upward bias in the trend of the volatility of the growth rate of total sales in the sample. This problem is particularly important in the last observation where a significant reduction in the number of firms in the sample in 2002 results in a substantial decline in total sales. This abnormally large negative growth rate causes the spike in the volatility for the last observation.

Second, our sample is substantially smaller than the US economy. As we move to lower levels of aggregation in the US economy, levels that better represent the size of our sample, the downward trend in aggregate volatility is difficult to observe. ${ }^{12}$ Figure 9 represents the average volatility of the growth rate of real sales for the two digit sectors in the US economy. ${ }^{13}$

To conduct the variance decomposition, the following notation is introduced. Let $\gamma_{X_{t}}$ be the growth rate of aggregate real sales in our sample deflated using the aggregate PPI, $\gamma_{x_{i t}}$ be the growth rate of real sales for firm $i$ and $s_{i t}$ be the share of sales for firm $i$ in the total sales for our

\footnotetext{
${ }^{12}$ On average, the sales of the firms in our COMPUSTAT sample represents 78 percent of GDP. Since the materials and energy share is approximately 50 percent of gross output, this means that the compustat sample represents about 39 percent of the economic activity in the US.

${ }^{13}$ The sectoral data is gathered from Jorgenson's 35 KLEM data set.
} 


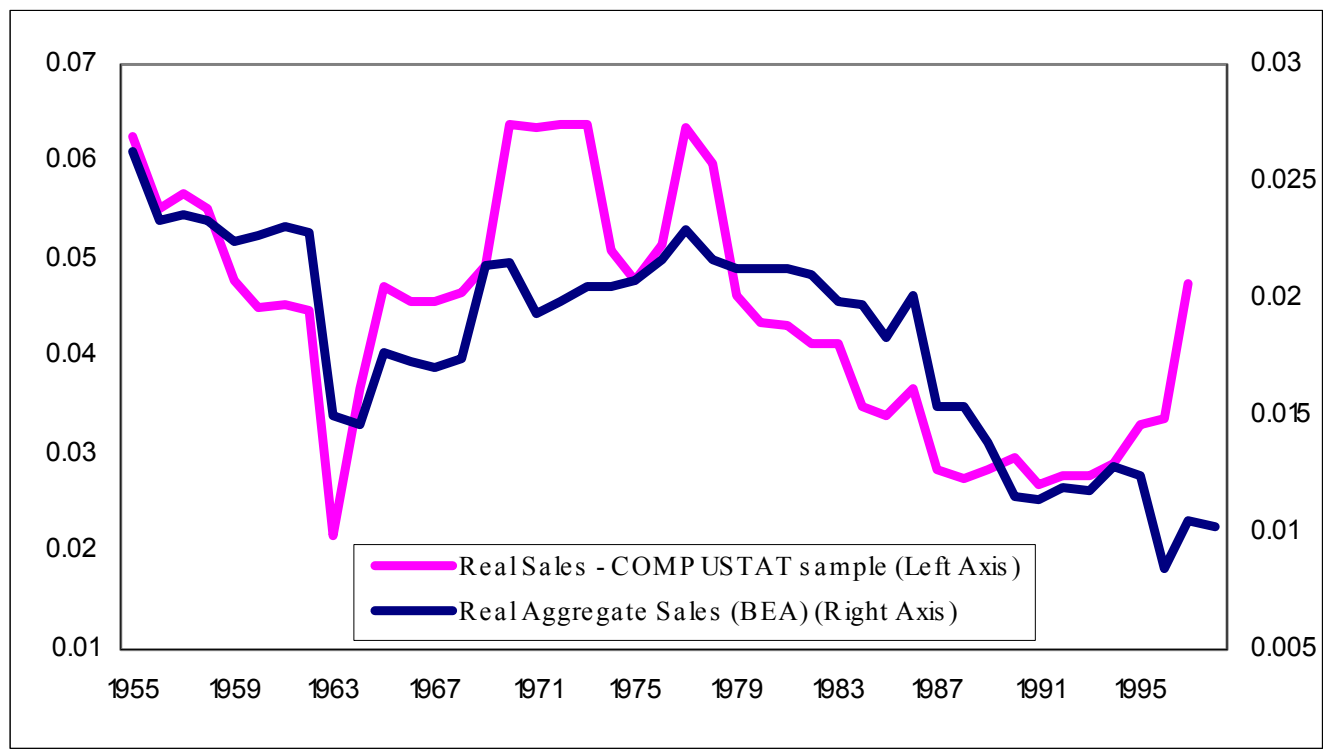

Figure 8: Comparison of Volatility for BEA Aggregate Sales and for COMPUSTAT Aggregate Sales

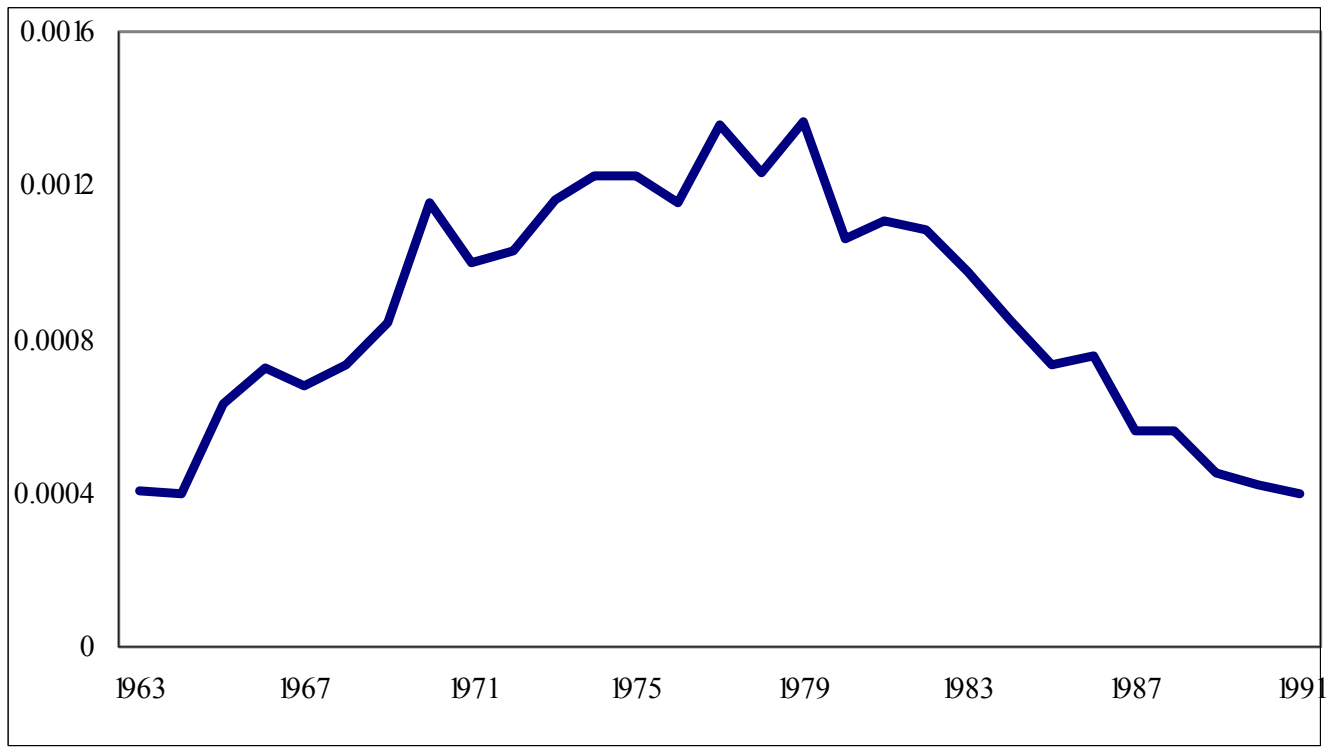

Figure 9: Average Variance of the Growth rate of Real Sales for 2-digit sectors. 
sample, all in year $t$. Also, let $V\left(\left[Z_{\tau}\right]_{t-4}^{t+5}\right)$ denote the variance of $\left\{Z_{t-4}, Z_{t-3}, \ldots Z_{t}, \ldots Z_{t+4}, Z_{t+5}\right\}$ for any generic variable $Z$ and $\operatorname{Cov}\left(\left[Z_{\tau}\right]_{t-4}^{t+5},\left[Y_{\tau}\right]_{t-4}^{t+5}\right)$ be the covariance between $\left\{Z_{t-4}, Z_{t-3}, \ldots Z_{t}, \ldots\right.$ $\left.Z_{t+4}, Z_{t+5}\right\}$ and $\left\{Y_{t-4}, Y_{t-3}, \ldots Y_{t}, \ldots Y_{t+4}, Y_{t+5}\right\}$.

Note that

$$
\gamma_{X_{t}}=\sum_{i} \gamma_{x_{i t}} s_{i t}
$$

Then, using the definition of the variance,

$$
V\left(\left[\gamma_{X_{\tau}}\right]_{t-4}^{t+5}\right) \equiv \frac{1}{10} \sum_{\tau=t-4}^{t+5}\left(\sum_{i} \gamma_{x_{i \tau}} s_{i \tau}-\frac{1}{10} \sum_{\tau=t-4}^{t+5} \sum_{i} \gamma_{x_{i \tau}} s_{i \tau}\right)^{2}
$$

For simplicity, suppose that $s_{i t}=s_{i}$ for all the firms $i$ and all years $t$. Then, $V\left(\left[\gamma_{X_{t}}\right]_{t-4}^{t+5}\right)$ can be written as follows:

$$
\begin{aligned}
V\left(\left[\gamma_{X_{\tau}}\right]_{t-4}^{t+5}\right) & =\frac{1}{10} \sum_{\tau=t-4}^{t+5}\left(\sum_{i} \gamma_{x_{i \tau}} s_{i}-\frac{1}{10} \sum_{\tau=t-4}^{t+5} \sum_{i} \gamma_{x_{i \tau}} s_{i}\right)^{2} \\
& =\frac{1}{10} \sum_{\tau=t-4}^{t+5}\left(\sum_{i} s_{i}\left(\gamma_{x_{i \tau}}-\frac{1}{10} \sum_{\tau=t-4}^{t+5} \gamma_{x_{i \tau}}\right)\right)^{2} \\
& =\frac{1}{10} \sum_{\tau=t-4}^{t+5}\left(\sum_{i} \sum_{j} s_{i} s_{j}\left(\gamma_{x_{i \tau}}-\frac{1}{10} \sum_{\tau=t-4}^{t+5} \gamma_{x_{i \tau}}\right)\left(\gamma_{x_{j \tau}}-\frac{1}{10} \sum_{\tau=t-4}^{t+5} \gamma_{x_{j \tau}}\right)\right) \\
& =\sum_{i} \sum_{j} s_{i} s_{j}\left(\frac{1}{10} \sum_{\tau=t-4}^{t+5}\left(\gamma_{x_{i \tau}}-\frac{1}{10} \sum_{\tau=t-4}^{t+5} \gamma_{x_{i \tau}}\right)\left(\gamma_{x_{j \tau}}-\frac{1}{10} \sum_{\tau=t-4}^{t+5} \gamma_{x_{j \tau}}\right)\right) \\
& =\underbrace{\sum_{i} s_{i}^{2} V\left(\left[\gamma_{x_{i \tau}}\right]_{t-4}^{t+5}\right)}_{\text {Variance Component }}+\underbrace{\left.\sum_{i} \sum_{j \neq i} s_{i} s_{j} \operatorname{Cov}\left(\left[\gamma_{x_{i \tau}}\right]_{t-4}^{t+5},\left[\gamma_{x_{j \tau}}\right]\right]_{t-4}^{t+5}\right)}_{\text {Covariance Component }}
\end{aligned}
$$

Hence, the variance of the growth rate of aggregate sales is decomposed into two terms - the first is related to the firm level variance of sales (variance component) and the second reflects the covariances between the growth rates of sales at different firms (covariance component). ${ }^{14}$ Figure 10 shows the evolution of these terms since 1950. There are two important remarks. First, the evolution of the volatility of the aggregate growth rate of sales in our COMPUSTAT sample is entirely driven by the covariance term. The variance term is an order of magnitude smaller and has no significant impact on aggregate volatility. In other words, to understand the evolution of

\footnotetext{
${ }^{14}$ The small discrepancy between the total variance and the sum of these two components is due to the time variation of the shares.
} 


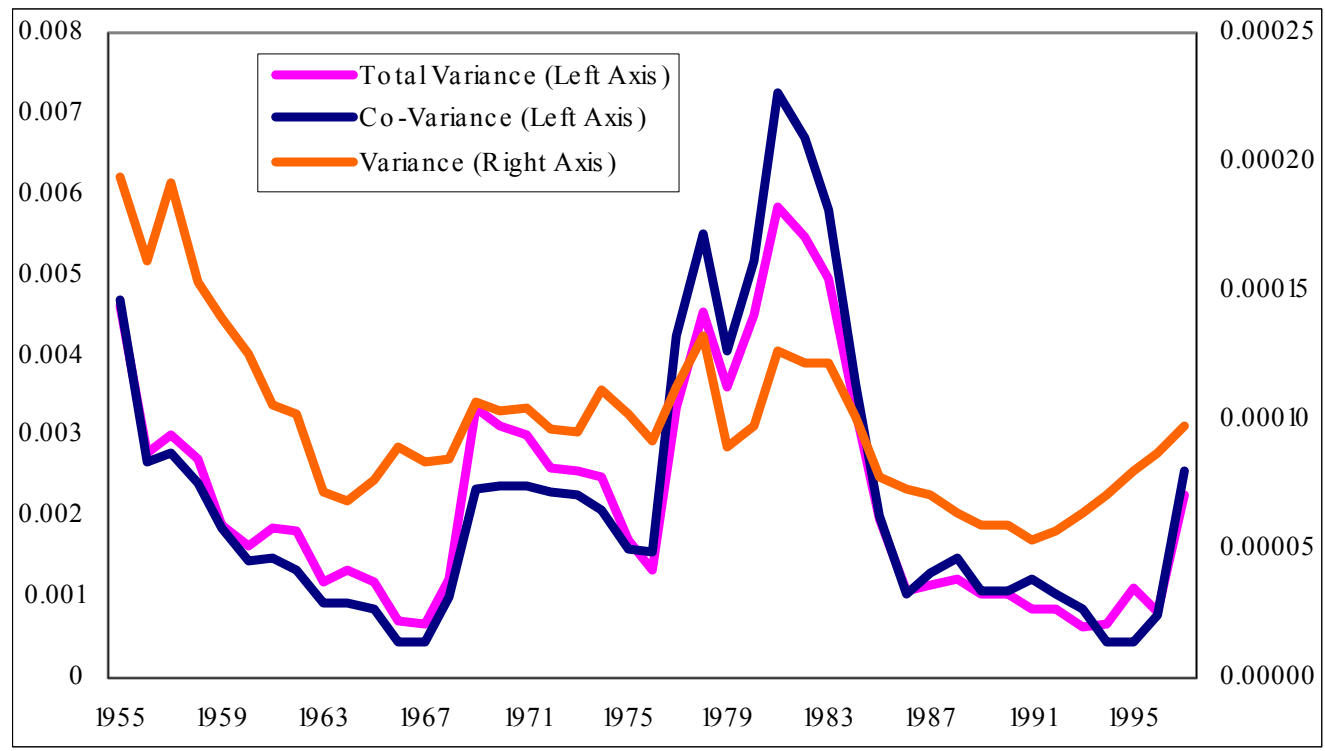

Figure 10: Variance Covariance Decomposition of Aggregate Growth Rate of COMPUSTAT Sales aggregate volatility, we need to understand the forces that drive the covariance of sales growth between firms as opposed to what affects the volatility of firm sales. Second, the decline in the variance component is entirely driven by the decline in the sum of squared shares $\left(\sum_{i} s_{i}^{2}\right)$ which is in turn due to the dramatic increase in the number of firms in our sample.

\section{Volatility over the cycle}

Finally, to conclude the empirical investigation, an issue of independent interest is examined: namely, the pro-ciclicality of volatility. To address this question, we follow Comin and Gertler [2003] by filtering non-farm business output and the various series of volatility using a band pass filter that removes frequencies lower than 50 years. This filter generates 6 cycles in the US post-war period. Such a filter is employed in favor of more standard (higher-frequency) filters such as the Hodrik-Prescott since movements at medium term frequencies are larger in comparison to movements at higher frequencies and are, in all likelihood, connected to the high-frequency fluctuations. ${ }^{15}$ We then compute the cross-correlogram between output and weighted and un-weighted measures of firm and aggregate-level volatility. Figure 11 displays the cross-correlograms. Two observations are made. First, volatility (both aggregate and firm-level) seems procyclical. Second, the primary dif-

\footnotetext{
${ }^{15}$ See Comin and Gertler [2003] for more information.
} 


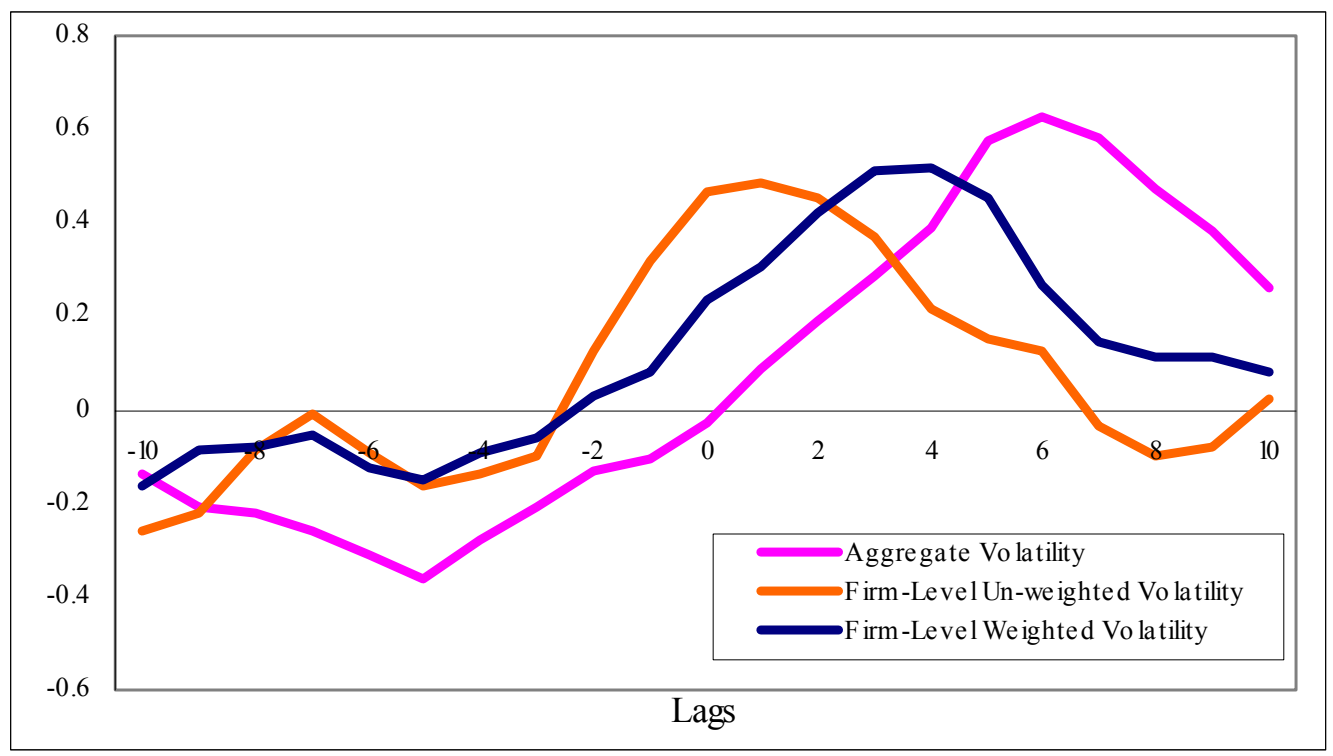

Figure 11: Cross-correlogram of filtered Non-Farm Business Output Output and Filtered Aggregate and Fim-level Volatility.

ference in terms of cyclical patterns is that, following a boom, firm-level volatility increases almost immediately while aggregate volatility increases with a lag. Specifically, the maximum response period is five to six years for aggregate volatility, three to four years for weighted firm-level volatility and less than a year for un-weighted firm-level volatility.

\section{Conclusions}

The U.S. economy has experienced opposite trends in volatility at the aggregate and firm level. At the aggregate level, several variables have become less volatile, with an interruption of this trend during the 70's and early 80's. At the micro level, however, the volatility of these very variables exhibits an upward trend. We believe the symmetric nature of these diverging trends (Figure 7) makes a common explanation (or set of explanations) likely.

Importantly, the upward trend in micro volatility has interesting implications when evaluating the proposed explanations for the decline in aggregate volatility. McConnell and Perez-Quiros [2000] proposed that new inventory management methods, such as just-in-time inventory management, are the source of the reduction in volatility in GDP. This mechanism operates at the firm level and, therefore implies that the volatility of output at the firm level should decline as well. This hypothesis 
is inconsistent with the evidence presented in this paper. ${ }^{16}$

Another line of research argues that part of the decline in aggregate volatility is due to a more effective monetary policy that helps stabilize shocks that hit the US economy. (Boivin and Gianonni [2002], Clarida, Gali and Gertler [2000], Congley and Sargent [2001], Gali, Lopez-Salido and Valles [2002], Primiceri [2002] and Sims and Zha [2002]). This argument has two drawbacks. First, from a quantitative perspective, an increase in the effectiveness of monetary policy can account for, at most, 30 percent of the reduction in aggregate volatility according to Stock and Watson [2002]. ${ }^{17}$ Second, it is difficult to find mechanisms that link a more active monetary policy to the increase in firm-level volatility. This hypothesis, thus, leaves un-explained the opposite trends observed in aggregate and firm-level volatility.

Since we have reasons to believe that the two symmetric trends are related, ${ }^{18}$ we devote the last paragraphs of the paper to present a brief sketch of a new explanation for the decline in aggregate volatility, one that simultaneously explains the increase in firm level volatility. ${ }^{19}$

To motivate our explanation, it is relevant to know some additional facts. First, the upward trend observed for the volatility of firm-level sales also holds for sales per worker and the growth rate of firm-level employment. Similarly, the decline in volatility of aggregate output is also true of aggregate productivity growth and aggregate employment growth. In our view, this means that the volatility of productivity is of primary importance. To explain the divergence in the evolution of the volatility of productivity growth at the firm and aggregate level, we build a model of endogenous productivity growth. In our model, productivity grows because there are two types of innovations. Embodied innovations are patentable innovations a la Aghion and Howitt [1992]. These research efforts lead firms to develop new versions of existing products or new products that replace the current market leaders. Such improvements in productivity lead to substantial firm-level volatility since incumbents incur losses while entrants enjoy capital gains. However, at the aggregate level,

\footnotetext{
${ }^{16}$ McConnell and Perez-Quiros [2000] stress as evidence in favor of their hypothesis the fact that there has been a larger decline in the volatility of the quarterly growth rate in manufacturing output than the volatility of the quarterly growth rate of manufacturing sales. However, at the annual frequency, Stock and Watson [2002] find that the decline in the volatilities of aggregate sales and output have been about the same for all production sectors: durables, nondurables, services, and structures.

${ }^{17}$ Stock and Watson analyze the volatility of quarterly growth. Surely, the role of a more active monetary policy in the reduction of volatility will be smaller when examining annual data.

${ }^{18}$ Comin and Philippon [2005] discusses in more detail these reasons.

${ }^{19}$ Comin and Mulani [2004] develops the model that underlies this explanation, provides some evidence and calibrates its quantitative importance.
} 
the effects of R\&D investments on volatility are relatively minor since individual gains and losses negate each other. ${ }^{20}$

To explain the movements in aggregate volatility, it is necessary to consider a second type of innovations. We denote these as disembodied innovations. Disembodied innovations satisfy two properties. First, they symmetrically affect both the firm that develops them as well as the rest of the firms. Second, a firm that develops a disembodied innovation (by and large) cannot appropriate the benefits enjoyed by the other firms when adopting it. This is because disembodied innovations such as the mass production system, new personnel and accounting practices, the use of electricity as the source of energy in a plant,... are hard to patent and easy to reverse-engineer.

These two properties are responsible for the interesting implications of our model. The fact that a disembodied innovation symmetrically affects all firms implies that it will have a large aggregate effect. Therefore, investments in the development of disembodied innovations may lead to substantial volatility in aggregate productivity growth. The fact that innovators cannot appropriate the social value of disembodied innovations implies that their incentives to develop them are increasing in the value of the firm. A small non-convexity in the costs of conducting disembodied innovations can imply that, in equilibrium, only large firms, which are the market leaders, invest in developing disembodied innovations.

Interestingly, the model predicts that there is a negative relationship between the aggregate investments in embodied and in disembodied innovations. This follows from: i) the value of market leaders is higher when the expected duration of their market leadership is longer; ii) market turnover is increasing in the investments in embodied innovations iii) for a market leader, the return from investing in a disembodied innovation is increasing in the value of its company..Hence, a force that leads the economy to invest more in developing embodied innovations may induce a decline in disembodied investments. In terms of volatility, one such shock can simultaneously induce a decline in aggregate volatility and an increase in firm-level volatility.

\footnotetext{
${ }^{20}$ Other investments in improving the sales of the company such as marketing and advertising expenses play a similar role to investments in the development of embodied innovations in this framework.
} 


\section{References}

[1] Blanchard, O. and J. Simon [2001]: "The Long and Large Decline in U.S. Output Volatility" Brookings Papers on Economic Activity, vol 1, 135-164.

[2] Boivin, J. and M. Giannoni [2002]: "Assessing Changes in the Monetary Transmission Mechanism," manuscript, Columbia University

[3] Campbell, J., M. Lettau, B. Malkiel, and Y. Xu [2001]: "Have Individual Stocks Become More Volatile? An Empirical Exploration of Idiosyncratic Risk" Journal of Finance, February.

[4] Clarida, R. J. Gali and M. Gertler [2000]: "Monetary Policy Rules and Macroeconomic Stability: Evidence and Some Theory," Quarterly Journal of of Economics, February, 147-180.

[5] Comin, D. [2000]: "An Uncertainty-Driven Theory of the Productivity Slowdown: Manufacturing" C.V. Starr wp \# 2000-16

[6] Comin, D. and S. Mulani [2004]: "Growth and Volatility" NYU mimeo.

[7] Comin, D. and T. Philippon [2005]: "The Rise in Firm-level Volatility: Causes and Consequences" NBER Macroeconomics Annual.

[8] Congley, T. and T. Sargent [2001]: "Evolving Post-World War II U.S. Inflation Dynamics" NBER Macroeconomics Annual, 331-372.

[9] Dornbusch, R., S. Fisher and P. Samuelson [1977]: "Comparative Advantage, Trade, and Payments in a Ricardian Model with a Continuum of Goods" American economic Review $67,5,823-839$.

[10] Gali, J. D. Lopez-Salido and J. Valles [2002]: "Technology Shocks and Monetary policy: Assessing the Fed's Performance" NBER w.p. \#8768.

[11] McConnell, M. and G. Perez-Quiros [2000]: "Output Fluctuations in the United States: What Has Changed Since the Early 1980's?" American Economic Review 90, no. 5 (December): 1464-76.

[12] Stock, J. and M. Watson [2002]: "Has The Business Cycle Changed And Why?" NBER Working Paper 9127 (September). 
Table 1: Average Firm-Level Volatility by Two-Digit Sectors and Decade

\begin{tabular}{|c|c|c|c|c|c|c|c|c|c|c|}
\hline \multirow[b]{2}{*}{$\underline{\text { Sector }}$} & \multicolumn{5}{|c|}{ Un-weighted } & \multicolumn{5}{|c|}{ Weighted } \\
\hline & 1950's & 1960's & 1970's & 1980's & 1990's & 1950's & 1960's & 1970's & 1980's & 1990's \\
\hline Agriculture & 0.26 & 0.30 & 0.34 & 0.39 & 0.38 & 0.57 & 0.73 & 0.90 & 1.00 & 1.06 \\
\hline Constructic & 0.25 & 0.21 & 0.22 & 0.23 & 0.19 & 0.35 & 0.36 & 0.39 & 0.40 & 0.37 \\
\hline Non-Durab & 0.17 & 0.23 & 0.28 & 0.34 & 0.35 & 0.28 & 0.33 & 0.42 & 0.47 & 0.47 \\
\hline Durable Mi & 0.21 & 0.22 & 0.26 & 0.30 & 0.31 & 0.32 & 0.34 & 0.37 & 0.40 & 0.41 \\
\hline Transporta 1 & 0.17 & 0.18 & 0.22 & 0.28 & 0.27 & 0.25 & 0.27 & 0.32 & 0.39 & 0.34 \\
\hline Communic & 0.04 & -0.01 & -0.01 & 0.05 & 0.06 & 0.21 & 0.21 & 0.23 & 0.28 & 0.29 \\
\hline Utilities & 0.11 & 0.13 & 0.18 & 0.21 & 0.24 & 0.20 & 0.22 & 0.29 & 0.32 & 0.35 \\
\hline Wholesale & 0.14 & 0.19 & 0.22 & 0.27 & 0.30 & 0.17 & 0.19 & 0.22 & 0.25 & 0.30 \\
\hline Retail Trad & 0.11 & 0.14 & 0.18 & 0.23 & 0.25 & 0.25 & 0.30 & 0.36 & 0.42 & 0.44 \\
\hline Finance anı & -0.04 & 0.01 & 0.09 & 0.09 & 0.08 & 0.34 & 0.51 & 0.63 & 0.60 & 0.61 \\
\hline Real Estate & -0.06 & 0.07 & 0.14 & 0.19 & 0.21 & 0.33 & 0.39 & 0.47 & 0.61 & 0.55 \\
\hline Services & 0.07 & 0.16 & 0.24 & 0.32 & 0.40 & 0.32 & 0.40 & 0.45 & 0.54 & 0.57 \\
\hline Public Adn & -0.01 & 0.05 & 0.13 & 0.10 & 0.13 & 0.45 & 0.53 & 0.58 & 0.66 & 0.68 \\
\hline
\end{tabular}

Note:

Measures shown are residual volatility after controlling for age, size and firm-specific fixed effects. 